\title{
A educação profissional e tecnológica na ótica de Lev Vygotsky: pressupostos teóricos e contribuições
}

\author{
Professional and technological education from the perspective of Lev Vygotsky: \\ theoretical assumptions and contributions
}

\author{
FEITOSA, Marivânia da Silva. Discente do curso de Mestrado em Educação Profissional e \\ Tecnológica \\ Instituto Federal de Educação Ciência e Tecnologia do Sertão Pernambucano- IF Sertão Campus Salgueiro. \\ Salgueiro - PE - Brasil. CEP: 56000-000 / Telefone: (82) 3214- 1749/ E-mail: marivania.feitosa@delmiro.ufal.br
}

\author{
MARTINS, João Paulo Lira. Discente do curso de Mestrado em Educação Profissional e \\ Tecnológica \\ Instituto Federal de Educação Ciência e Tecnologia do Sertão Pernambucano- IF Sertão Campus Salgueiro. \\ Salgueiro - PE - Brasil. CEP: 56000-000 / Telefone: (89) 3462-1005/ E-mail: joaopaulolira@ifpi.edu.br
}

\section{TAVARES, Suemys Luize Pansani. Discente do curso de Mestrado em Educação Profissional e Tecnológica \\ Instituto Federal de Educação Ciência e Tecnologia do Sertão Pernambucano- IF Sertão Campus Salgueiro. Salgueiro - PE - Brasil. CEP: 56000-000 / Telefone: (87) 3851-5291/ E-mail: slptavares@hotmail.com}

\section{LEÃES, Paulo Garcez. Mestre/Pedagogo}

Instituto Federal de Educação Ciência e Tecnologia do Sertão Pernambucano- IF Sertão Campus Salgueiro. Salgueiro - PE - Brasil. CEP: 56000-000 / Telefone: (87) 99664-3349 / E-mail: paulo.leaes@ifsertao-pe.edu.br

\section{OLIVEIRA, Cristiane Ayala de. Doutora/Tecnóloga em Agroindústria}

Instituto Federal de Educação Ciência e Tecnologia do Sertão Pernambucano- IF Sertão Campus Salgueiro. Salgueiro - PE - Brasil. CEP: 56000-000. / Telefone: (87) 99664-3349 / E-mail: cristiane.ayala@ifsertaope.edu.br

\section{RESUMO}

A presente pesquisa objetiva estudar como Vygotsky e a teoria sociocultural podem contribuir para a atividade pedagógica dentro da Educação Profissional e Tecnológica. Os conceitos de Vygotsky de internalização, mediação e zona de desenvolvimento proximal consideram alunos e professores como agentes de transformação do meio social. 0 autor também destaca que, além de transformar o meio, os sujeitos são influenciados por este. 0 referido artigo trata-se de uma pesquisa bibliográfica, que analisa e discute os dados a partir das discussões fomentadas em artigos, livros e outros registros acessíveis. Em nossas buscas, procuramos os estudos fundamentados nos pressupostos da teoria de Vygotsky e sua aplicabilidade na Educação Profissional. Portanto, por meio do estudo realizado, foi possível confirmar como a obra de Vygotsky, quando aplicada de forma eficaz dentro da atividade pedagógica, colabora coma uma eficiente teoria para os processos de ensino aprendizagem na Educação Profissional e Tecnológica.

Palavras-chave: Educação, teoria Vygotskyana, aprendizagem significativa.

\begin{abstract}
The present research aims to study how Vygotsky and sociocultural theorycan contribute to the pedagogical activity with in Vocational and Technological Education. Vygotsky's concepts of internalization, mediation and zone of proximal development consider students and teachers as agents of transformation of the social environment. The author also points out that, in addition to transforming the environment, subjects are influenced by it. This article is a bibliographical research that analyzes and discusses the data from the discussions promoted in articles, books and other accessible records. In our searches, we look for studies base dont heas sumptions of Vygotsky's theory and its applicability in Vocational Education. In addition, we cover research on Professional and Technological Education, providing a brief description of the historical context of that. There fore, through the ful filled study, it was possible to confirm how the work of Vygostsky, when applie deffectively within the pedagogical activity, collaborates with an efficient theory for the processes of teaching-learning in Vocational and Technological Education.
\end{abstract}

keywords: Education, Vygotskyana theory, meaningfullearning. 
FEITOSA, M. da S.; MARTINS, J. P. L.; TAVARES, S. L. P.; LEĀES, P. G.; OLIVEIRA, C. A. de.(2019). A educação profissional e tecnológica na ótica de Lev Vygotsky: pressupostos teóricos e contribuições

\section{Introdução}

Lev Semyonovich Vygotsky foi um psicólogo russo nascido em 1896, que durante anos de estudos e em diferentes áreas, produziu mais de 200 artigos científicos. Este estudioso tinha como principal objetivo entender como ocorria o desenvolvimento das funções psicológicas superiores dos seres humanos, em que afirma ter vinculação com o processo de pensamento, linguagens, memórias, simbologias, dentre outros. A máxima da obra de Vygotsky é afirmar que o homem não nasce humano, mas ele se humaniza. Para este autor, o homem é visto como um ser histórico-cultural e como agente de transformação do meio em que vive.

De forma geral, segundo Vygotsky, quando se pensa no desenvolvimento da criança, deve-se levar em consideração o contexto social em que ela está inserida, pois as crianças não são universalizadas e possuem o adulto como mediador do conhecimento. É nesse contexto de ensinoaprendizagem que surgiram os principias conceitos que norteiam a obra de Vygotsky, entre eles: a saber: a Internalização, a Mediação e a Zona de Desenvolvimento Proximal. 0 autor faz referência à fase infantil, mas seus pressupostos podem ser aplicados nas fases subsequentes, inclusive na educação profissional. Sendo assim, a presente pesquisa objetiva refletir e talvez aprimorar as discussões em torno da teoria de Vygotsky e suas contribuições para os processos de aprendizagem na educação profissional.

No Brasil, conforme visualizar-se-á neste artigo, os estudos que tratam da gênese da educação profissional revelam que esta foi pensada para atender às classes menos favorecidas. Para aqueles que tinham maior poder aquisitivo, a oferta era do ensino propedêutico, o qual permitia prosseguir com os estudos. Autores como Vieira. J e Vieira. M (2014) pontuam que é preciso ressignificar a educação profissional. Diante do exposto, e levando em consideração que a Educação Profissional e Tecnológica (EPT), além da preparação dos jovens para o mercado de trabalho, deve contribuir, também, para uma formação crítica dos sujeitos, buscando ser norteada pelos princípios de uma educação realmente emancipadora, que esta pesquisa foi delineada. Inferimos, então, que os estudos de Vygotsky podem ofertar imperiosas reflexões para o processo de ensino-aprendizagem na EPT, conforme veremos no decorrer deste trabalho.

No que tange à estrutura do artigo, este está dividido em quatro seções. Na primeira, mencionamos acerca da história e a evolução da Educação Profissional e Tecnológica no Brasil (de 1909 até os dias de hoje). Na segunda parte, é abordada a importância da teoria histórico-cultural, além de descrever como ela é imprescindível dentro do processo de ensino-aprendizagem. A terceira seção caracteriza os principais conceitos da obra de Vygotsky e sua influência dentro da atividade pedagógica da EPT e, a última parte, traz a análise e discussões do que foi abordado durante os três primeiros capítulos.

\section{Breve histórico da educação profissional}

A Educação Profissional e Tecnológica (EPT) é uma modalidade de ensino que oferece tanto curso de formação inicial e continuada, quanto cursos técnicos, que são cursos de longa duração. 
FEITOSA, M. da S.; MARTINS, J. P. L.; TAVARES, S. L. P.; LEĀES, P. G.; OLIVEIRA, C. A. de.(2019).

A educação profissional e tecnológica na ótica de Lev Vygotsky: pressupostos teóricos e contribuições

Atualmente, estes cursos são ofertados principalmente pelos Institutos Federais de Educação, Ciência e Tecnologia. Nesse contexto pode-se dizer que a história do ensino técnico no Brasil mistura-se com a história dos Institutos Federais de Educação. Segundo Caetano e Linsingen (2011) o ponto de partida dessas instituições foram as escolas agrícolas e as escolas de aprendizes e artífices. Essas escolas foram criadas em 1909, pelo então Presidente do Brasil na época, a partir do decreto $n^{\circ} 7.566$ de 1909, como veremos nas explicitações que seguem.

Com o decreto $n^{\circ} 7.566$ de 23 de setembro de 1909, o então presidente da República dos Estados Unidos do Brasil, Nilo Peçanha, cria nas capitais dos estados as Escolas de Aprendizes Artífices, destinados ao ensino profissional de nível primário e de natureza gratuita com o objetivo de atender aos "desfavorecidos de fortunas”, tornando-os úteis a nação. (ARAÚJO, 2016, p.24)

Os desfavorecidos de fortunas eram as crianças entre 10 e 13 anos de famílias pobres e que aprendiam algum ofício, como sapataria, carpintaria, etc., e que, além de oferecer educação primária, tinha também como objetivo diminuir a criminalidade da época.Segundo Garcia et. al (2018, p. 7) "ao longo do ano de 1910, foram inauguradas 19 Escolas de Aprendizes e Artífices, presentes em todo o território nacional [...]".

Já no final da década de 1920, a Política de Substituição de Importações precisou com urgência qualificar a mão de obra local para a crescente industrialização que emergia no país. Segundo Lima (2011, p. 35), essa política “[...] se amparava pelas multinacionais que se instalavam no país para a produção de bens industrializados [...]".

Em 1937 ocorreu a primeira mudança no nome das escolas de aprendizes e artífices, que passaram a ser chamadas de Liceus Industriais e que, segundo Araújo (2016) tornaram-se dever do Estado, passando assim a ser tratados como políticas públicas. De fato, ainda fica evidente, que os Liceus Industriais ainda eram destinados aos menos favorecidos. Sendo assim, o ensino profissionalizante ficou por anos sendo estigmatizado como uma forma de ensino destinado exclusivamente aos mais pobres.

Em 1942, foi instituída pelo então Ministro da Educação da época Gustavo Capanema, a Reforma Capanema:

[...] instituída através das chamadas Leis Orgânicas (Decretos-Lei), envolvendo os seguintes ramos do ensino: secundário, industrial, comercial, agrícola, normal e primário. Foi um período em que a dualidade na educação se expressava, na medida em que os egressos da educação média profissionalizante só tinham acesso ao ensino superior, na mesma carreira, não podendo escolher outra, e até mesmo este acesso restrito era extremamente dificultado, o que fazia com que poucos alunos tivessem oportunidade de cursar o ensino superior. Por outro lado, os alunos que terminavam o secundário, podiam prosseguir ao superior, sem restrição alguma. (PAMPLONA, 2008, p. 17).

Como mencionam os autores, foi nessa época que o ensino industrial passou a se organizar em regime de segundo grau, destinado a preparação de trabalhadores que iriam atuar principalmente nas indústrias, com o objetivo de formar mão de obra qualificada para agir no setor produtivo. Nesse período, ainda ocorreu mais uma mudança na nomenclatura e os Liceus Industriais passaram a ser denominados de Escolas Industriais e Técnicas. 
FEITOSA, M. da S.; MARTINS, J. P. L.; TAVARES, S. L. P.; LEĀES, P. G.; OLIVEIRA, C. A. de.(2019). A educação profissional e tecnológica na ótica de Lev Vygotsky: pressupostos teóricos e contribuições

Ainda no mencionado período, o Decreto-Lei n 4.408 de 22 de janeiro de 1942 cria o SENAI Serviço Nacional de Aprendizagem Industrial Já o Decreto-Lei 9.613/46 criou os estabelecimentos de ensino de escolas agrícolas industriais e o Decreto-Lei $n^{\circ} 8.621$ de 10 de janeiro de 1946 criou o SENAC - Serviço Nacional de Aprendizagem Comercial. (BRASIL, 2018). Importante destacar que as escolas agrícolas industriais foram a base para a criação do que hoje chamamos Institutos Federais de Educação.

Em 1959, as Escolas Industriais e Técnicas passaram a ser chamadas de Escolas Técnicas Federias, transformando-se em autarquias e ganhando mais autonomia tanto de gestão, quanto de didática. Isso aconteceu no período do governo Juscelino Kubitschek, sendo uma consequência da chegada ao país da indústria automobilística que carecia mão de obra fortemente qualificada.

Em 1961, foi promulgado o Decreto-Lei n ${ }^{\circ} 4.024 / 61$ que segundo Moura (2007), permitiu que os alunos concludentes dos cursos de Educação Profissional pudessem continuar os estudos no Ensino Superior. Ainda em Moura (2007, p. 11) é revelado que: “em 1971 há uma profunda reforma da educação básica promovida pela Lei $n^{\circ} 5.692 / 71$, que se constituiu em uma tentativa de estruturar a educação de nível médio brasileiro como sendo profissionalizante para todos”. Esse Decreto-Lei trata exclusivamente da Lei de Reforma de Ensino de $1^{\circ}$ e $2^{\circ}$ graus, que tinha como finalidade a profissionalização de todo Ensino Secundário, a parir da união do ensino primário e médio.

Já em 1978, um Decreto-Lei transformou as Escolas Técnicas Federais dos estados do Rio de Janeiro, Paraná e Minas Gerais em Centros Federais de Educação, mais conhecidos como CEFET's, que ofertavam os cursos de Engenharia Industrial, Tecnólogos, e cursos técnicos do $2^{\circ}$ grau. Esta mudança confere àquelas instituições mais uma atribuição: formar engenheiros de operação e tecnólogos, processo esse que se estende às outras instituições bem mais tarde. (BRASIL, 2009, p. 5)

A partir da redemocratização do país com a promulgação da Constituição Federal de 1988, no âmbito educacional, houve uma reestruturação das políticas públicas voltadas para a educação.

Em 1994, a Lei n 8.948, de 8 de dezembro dispõe sobre a instituição do Sistema Nacional de Educação Tecnológica, transformando, gradativamente, as Escolas Técnicas Federais e as Escolas Agrotécnicas Federais em Centros Federais de Educação Tecnológica - CEFETs. “ [...] Em 20 de novembro de 1996 foi sancionada a Lei 9.394 ,considerada como a segunda LDB, que dispõe sobre a Educação Profissional num capítulo separado da Educação Básica [...]”. (BRASIL, 2009, p. 5).

Vale destacar que, como Políticas Públicas importantes garantidas pela Constituição de 1988, temos a criação do Plano Nacional de Educação e da Base Nacional Curricular Comum. Porém, de encontro com essa expansão da reestruturação educacional, Garcia et. al (2018, p.9) destaca que: "em 1998, foram proibidas as construções de novas escolas federais pelo governo federal baseado na Lei n. 8.948, de 08 de dezembro de 1994." Essa Lei só foi revogada em 2005, quando os Centros de Educação tiveram o seu maior grau de valorização.

Foi nesse ano de 2005 que o então Presidente Lula anunciou o Plano de Expansão das Redes de Educação Profissional e Tecnológica, de início, com a construção de 65 unidades. De acordo com Pacheco e Morigi (2012), com o lançamento do Plano de Desenvolvimento da Educação do MEC de 2007, o crescimento dos IF's passou a fazer parte dos programas de expansão do governo.

Em 29 de dezembro de 2008, com o Decreto de Lei $n^{\circ} 11.892$, foram criados os Institutos 
FEITOSA, M. da S.; MARTINS, J. P. L.; TAVARES, S. L. P.; LEĀES, P. G.; OLIVEIRA, C. A. de.(2019).

A educação profissional e tecnológica na ótica de Lev Vygotsky: pressupostos teóricos e contribuições

Federais de Educação Ciência e Tecnologia que, segundo Pacheco et. al (2012, p. 5) , “representam um importante desafio para a educação profissional e tecnológica, porquanto, ao se procurar romper com a tradicional missão de vincular essa modalidade da Educação às demandas exclusivas do mercado, entra em cena, a necessidade de construção de um novo paradigma para a mesma". Para os autores, fica claro que os Institutos Federais não vão mais atuar apenas nas suas áreas de ensino profissionalizante, mas unindo ensino, pesquisa e extensão, assemelhando-se assim às universidades Federais, mas resguardadas as suas áreas de atuação. Após revisitarmos o percurso histórico da educação profissional, destacaremos, a seguir, os conceitos de alguns autores acerca dessa modalidade de ensino.

De acordo com Caetano e Linsingen (2011) o Ensino Profissional e Tecnológico (EPT) tem como base fundamental ofertar vagas para jovens e profissionais que queiram se capacitar para o mercado de trabalho. Ficando evidente, assim, que a EPT busca a integração entre escola e trabalho e como principal desafio transformar a teoria em competências para o trabalho. No entanto, outros autores defendem que a educação profissional deve-se apresentar numa visão mais holística, em que os educandos não sejam apenas preparados para mundo do trabalho, mas também para a vida. Essa reflexão é compartilhada pelos autores abaixo, quando citam a relevância do ensino médio integrado na educação profissional. Então, para Araújo e Frigotto (2015, p.68):

$\mathrm{Na}$ perspectiva da integração, a utilidade dos conteúdos passa a ser concebida não na perspectiva imediata do mercado, mas tendo como referência a utilidade social, ou seja, os conteúdos são selecionados e organizados na medida de sua possibilidade de promover comportamentos que promovam o ser humano e instrumentalizem o reconhecimento da essência da sociedade e a sua transformação. Procura-se, com isto, formar o indivíduo em suas múltiplas capacidades: de trabalhar, de viver coletivamente e agir autonomamente sobre a realidade, contribuindo para a construção de uma sociabilidade de fraternidade e de justiça social.

Bispo (2015) também destaca que devido às crescentes desigualdades sociais existentes no país, tem-se a necessidade da busca de alternativas para colocarem os jovens no mercado de trabalho, a partir de uma educação profissional de qualidade, que além da geração de emprego, os jovens possam participar em situação de igualdade da vida política, econômica e social podendo assim, colher os frutos dessa participação. Isso mostra de forma eficaz a importância da educação profissional e tecnológica como ponte entre a educação e a sociedade, na formação de profissionais capacitados para o mundo do trabalho e para a vida.

Após esta explanação acerca da história da educação profissional, nosso foco será compreender a relevância da Teoria Histórico-Cultural para os processos de ensino-aprendizagem na educação. É o que delinearemos agora.

\section{Teoria Histórico-Cultural}

O presente capítulo dedica-se a uma breve abordagem sobre a perspectiva histórico-cultural de Lev Semyonovich Vygotsky e as suas contribuições, principalmente, no campo da psicologia e da educação. Vale salientar que seus estudos não se reduziram apenas a esses campos, adentrou pela 
FEITOSA, M. da S.; MARTINS, J. P. L.; TAVARES, S. L. P.; LEĀES, P. G.; OLIVEIRA, C. A. de.(2019).

A educação profissional e tecnológica na ótica de Lev Vygotsky: pressupostos teóricos e contribuições

antropologia, linguística, neurologia, filosofia e sociologia. No primeiro momento, debruçaremos sobre os percursos intelectuais e as influências marcantes da teoria do mencionado autor. Depois, transitaremos nas suas principais linhas de pesquisa, como a abordagem sóciointeracionista, as fundamentais teses postuladas pelo teórico, evidenciando quatro pontos essenciais: a interação, mediação simbólica, relação entre o pensamento e linguagem, zona de desenvolvimento proximal.

Apesar da sua curta existência, Lev Semyonovich Vygotsky, que faleceu aos 37 anos, decorrente de tuberculose, é notória a qualidade de seus escritos e as contribuições deixadas para os mais diversos ramos de estudo, suas obras marcadas pela interdisciplinaridade, não foi um acaso, e sim, fruto do processo de estudo ao longo da sua trajetória de vida É evidente que todos caminhos educacionais trilhados, reverberaram na qualidade dos seus trabalhos, tanto na vida acadêmica, como vida profissional, traçando, assim, a sua principal marca: trazer a cultura e a natureza humana para o desenvolvimento do ser. Assim, como assinala Rego (1995, p.26), "um dos pontos centrais de sua teoria é que as funções psicológicas superiores são de origem sociocultural e emergem de processos psicológicos elementares, de origem biológica (estruturas orgânicas)"

Essa avidez pelos estudos, aproximou Vygotsky de teóricos que influenciaram diretamente na construção dos seus escritos, dentre eles, os pesquisadores soviéticos contemporâneos como K.N Kornilov e P.P. Blonsk, que inclinavam-se para mesma linha de pensamento, centrada nas abordagens históricas do desenvolvimento humano. É de suma importância destacar, também, a influência de Marx e Engels, como fonte científica de extrema valia:

Podemos identificar os pressupostos filosóficos, epistemológicos e metodológicos de sua obra na teoria dialético-materialista. As concepções de Marx e Engels sobre a sociedade, o trabalho humano, o uso dos instrumentos, e a interação dialética entre o homem e natureza serviram como fundamento principal às suas teses sobre o desenvolvimento humano profundamente enraizado na sociedade e na cultura (REGO, 1995, p.32).

Como já citado, Vygotsky foi detentor de uma pluralidade de estudos em torno dos mais diversos campos: neurológico, antropológicos, psicológicos, sociológicos, filosóficos e linguísticos. Logo, analisar os caminhos teóricos percorridos durante a sua breve existência, ainda que de maneira sucinta, como proposto neste capítulo, faz- se necessário debruçar sobre alguns aspectos fundamentais, onde perpassaremos pelo seu campo de pesquisa baseado na teoria histórico-cultural, conhecida como sociointeracionista, as funções psicológicas superiores, como também as suas linhas de pesquisa ligadas a história social e a mediação simbólica, a relação entre o pensamento e a linguagem, a linguagem escrita, a zona de desenvolvimento proximal, a formação de conceito e a sua relação com o desempenho no ensino escolar. Sendo esses, pontos prioritários para clarificar com brevidade alguns dos principais fundamentos vygotskyano.

No que tange aos estudos da cultura como parte da natureza humana, Rego (1995), no livro, Vygotsky: Uma perspectiva histórica cultural da educação aborda uma reflexão sobre as principais ideias de Vygostsky, postas nas suas obras, cinco teses básicas que promovem um maior entendimento das linhas de pesquisa do teórico, sendo elas: interação dialética, que consiste na relação do homem, o meio sociocultural e o seu poder de transformação do espaço e ao mesmo tempo a transformação de si, ou seja, "quando o homem modifica o ambiente através de seu 
FEITOSA, M. da S.; MARTINS, J. P. L.; TAVARES, S. L. P.; LEĀES, P. G.; OLIVEIRA, C. A. de.(2019).

A educação profissional e tecnológica na ótica de Lev Vygotsky: pressupostos teóricos e contribuições

próprio comportamento, essa mesma modificação vai influenciar seu comportamento futuro". (Ibidem,1995, p.41). A segunda tese retoma a questão da internalização da cultura, estabelecendo uma referência a anterior, a relação do homem com o meio, tendo as funções psicológicas como parte de uma origem cultural, pois são originárias da sua posição social e cultural, como parte da natureza humana. Na terceira tese, trata-se das bases biológicas, e grande plasticidade do cérebro, sendo este capaz de ser moldado ao longo da história.

Outro ponto relevante na obra de Vygotsky, é o que discerne sobre a mediação, que são instrumentos técnicos construídos historicamente que interligam o ser humano e mundo. De acordo com a autora (Ibidem,1995, p.42), “o pressuposto da mediação é fundamental na perspectiva sócio histórica justamente porque é através dos instrumentos e signos que os processos de funcionamento psicológico são fornecidos pela cultura". Para Vygotsky, o sistema simbólico que compõem significativamente esse papel é a linguagem pelo curso histórico social, pela sua complexidade e a organização dos signos. E findando as principais ideias postuladas, reflete na relação com consciência humana também como agente no processo histórico social.

Já a interação, se dá através da relação do homem com o meio seja ele físico, seja ele social, no entanto, é fomentado por um agente mediador, entendido como mediador simbólico. Para Vygotsky, segundo Moreira (1999, p.112) "interação é fundamental para o desenvolvimento cognitivo e linguístico de qualquer indivíduo". Ainda segundo Vygotsky, os elementos dessa mediação, são os instrumentos e os signos, que corresponde respectivamente a uma orientação externa e outro interna, isto é, o instrumento exerce a função de regular as ações sobre os objetos, já os signos influem as ações sobre o psiquismo das pessoas (Ibidem, 1995), desta forma um tem ação sobre a natureza e o outro diretamente sobre o indivíduo, sendo parte das construções sócio históricas e culturais.

Os instrumentos e os signos são construções sócio históricas e culturais; através da apropriação (internalização) destas construções, via interação social, o sujeito se desenvolve cognitivamente. Quanto mais o indivíduo vai utilizando signos, tanto mais vão se modificando, fundamentalmente, as operações psicológicas das quais ele é capaz. Da mesma forma, quanto mais instrumentos ele vai aprendendo a usar, tanto mais se amplia, de modo ilimitado, a gama de atividades nas quais pode aplicar suas novas funções psicológicas.(ibidem,1999, p.111).

Dentre as questões da mediação, Vygotsky destacou a linguagem como o mais importante sistema de signos, que desenvolve o cognitivo, porque libera dos vínculos contextuais imediatos (MOREIRA, 1999).

Em análise das teorias vygotskiana, é perceptível a importância dada a dimensão social, não que tenha ignorado o caráter biológico, no entanto, esse processo de interação social, a relação entre o homem e meio, mediada por elementos como os instrumentos e signos, fazem parte do desenvolvimento e da aprendizagem, discussão que permeia em grande parte dos estudos de Vygotsky. Ainda, segundo o autor, há dois níveis de desenvolvimento, o desenvolvimento real ou efetivo e o desenvolvimento em potencial. Sob essa ótica, Rego (1995) explica que o nível de desenvolvimento real ou efetivo é aquele que capitado e aprendido, não demandaria do auxílio do outro, visto que já aprendido as funções ou capacidades, no que difere do desenvolvimento 
FEITOSA, M. da S.; MARTINS, J. P. L.; TAVARES, S. L. P.; LEĀES, P. G.; OLIVEIRA, C. A. de.(2019).

A educação profissional e tecnológica na ótica de Lev Vygotsky: pressupostos teóricos e contribuições

potencial, que é aquele que a criança é capaz de fazer, no entanto, ainda necessita de diálogo, ajuda e colaboração, cooperação de uma outra pessoa.

Diante dessa perspectiva, entre o desenvolvimento real e o potencial, é que Vygotsky desenvolveu um dos pontos emblemáticos das suas obras, a Zona de Desenvolvimento Proximal, como enfatiza o autor que segue:

Entre esses dois níveis, situa-se a zona do desenvolvimento próximo, ou seja, distância, metafórica, entre o nível de desenvolvimento real e o nível de desenvolvimento próximo, ou melhor dizendo, o percurso a ser feito entre o que o indivíduo já domina e o que está em processo de consolidação (FITTIPALDI, 2016, p.51).

Portanto, analisar a perspectiva histórica cultura vygotskiana, é reconhecer a contribuição deixada principalmente no ramo pedagógico. Salientamos, que os conceitos destacados nessa seção, como zona de desenvolvimento proximal, interação e mediação também serão abordadas no tópico que segue, pois são pressupostos teóricos relevantes de Vygotsky para os processos de ensinoaprendizagem na educação profissional e tecnológica e que necessitam de uma maior ênfase.

Sendo assim, após essa discussão acerca da teoria histórico-cultural, debateremos, agora, sobre a teoria vygotskyana e sua aplicabilidade na educação profissional e tecnológica. É o delineamento que segue.

\section{Material e métodos}

O presente artigo trata-se de uma pesquisa bibliográfica, que analisa e discute os dados a partir das discussões fomentadas em artigos, livros, dissertações e revistas. Em nossas buscas, procuramos os estudos fundamentados nos pressupostos da teoria de Vygotsky e sua aplicabilidade na Educação Profissional. Além disso, percorremos pesquisas acerca da Educação Profissional e Tecnológica, tecendo uma breve descrição do contexto histórico desta. Realizamos ainda, um estudo acerca da teoria histórico-cultural, que destaca as interações sociais como sendo de suma importância para o desenvolvimento do indivíduo. Neste, destacamos as reflexões sobre as Teorias da Aprendizagem compartilhadas, principalmente, por Moreira (1999).

Quanto à forma de abordagem, entende-se que é de cunho qualitativo, pois em conformidade com os estudos de (PRODANOV, FREITAS, 2013) esta privilegia não a quantificação dos dados, mas sim, sua descrição, buscando um retrato amplo dos elementos presentes na realidade estudada. Em busca dessa amplitude na pesquisa, procuramos, sobretudo, compreender a teoria de Vygotsky. Para isso, recorremos aos autores Rego (1995), Fontana e Cruz (1999), Vygotsky (1991) Andrade (2007) Silva (2007) e Oliveira e Silva (2018). Os autores, agora mencionados, contribuíram para um entendimento acerca da teoria vygotskyana e dos principais conceitos desenvolvidos neste trabalho, como: Mediação, Zona de Desenvolvimento Proximal e Interação. Faz necessário destacar, também, autores como Diesel, Martins e Baldez (2017), as quais abordam a aprendizagem focada nas Metodologias Ativas e a relevância deste método para autonomia do sujeito. Barato (2008), também contri- 
FEITOSA, M. da S.; MARTINS, J. P. L.; TAVARES, S. L. P.; LEĀES, P. G.; OLIVEIRA, C. A. de.(2019).

A educação profissional e tecnológica na ótica de Lev Vygotsky: pressupostos teóricos e contribuições

buiu para esclarecer sobre a Teoria da Atividade e Comunidades Práticas, teorias essas de relevância para a aplicabilidade na educação profissional, como veremos no decorrer deste estudo.

No que tange aos objetivos, esta pesquisa se caracteriza como exploratória, pois com revela Gil (2007), este tipo de estudo visa buscar uma maior familiaridade do pesquisador com o problema a ser estudado, tornando-o mais explícito. Sendo assim, nosso objetivo é refletir como a teoria de Vygotsky pode ampliar as possibilidades de aprendizagem na educação profissional e tecnológica. Como há uma melhor explicitação do objeto de estudo, podemos dizer que pesquisas com este objetivo também proporcionam, aos futuros pesquisadores da temática, uma compreensão mais ampla e precisa da realidade estudada.

As pesquisas tornam-se elementos primordiais para geração de conhecimentos, como assinala Severino (2007, p. 34): "Com efeito, a pesquisa é fundamental, uma vez que é através dela que podemos gerar o conhecimento a ser entendido necessariamente entendido como a construção dos objetos de que se precisa apropriar humanamente". É com este intuito, de reflexões e aprimoramentos das discussões da teoria de Vygotsky e suas contribuições para a educação profissional, que a pesquisa se fundamenta.

\section{Resultados e discussão}

\section{Teoria vygotskyana e a educação profissional}

Antes de adentrarmos nas discussões acerca das contribuições da teoria de Vygotsky para a educação profissional, faz-se necessário apresentarmos uma breve reflexão acerca da história da educação brasileira, para entendermos que é necessário vislumbrarmos novos caminhos, em que, o foco, seja a promoção de uma pedagogia emancipadora do sujeito. É o caminho que delinearemos agora.

Revisitando a história, percebe-se que a escola não foi institucionalizada para atender a todas as classes sociais, pois de acordo com Moura, Lima Filho e Silva (2015, p.1059) "a escola foi inicialmente um luxo, porque era para atender apenas a classe dos dirigentes". Para os filhos dos trabalhadores, restavam apenas os liceus para aprender uma determinada profissão. Infere-se, daí, o caráter dual da educação. E, essa dualidade, podemos vislumbrar nos espaços escolares quando há uma referenciação maior da cultura elitista em detrimento da popular, destaque para o conhecimento teórico e menos valorização do saber prático, ensino propedêutico para a classe elitista e o técnico para a trabalhadora, professores licenciados para uns e profissionais com notório saber para outros, dentre outras formas dicotômicas.

Para Vieira. J e Vieira. M (2014) é preciso dar um novo significado a educação profissional, pois durante muitos anos as instituições de educação profissional eram vistas apenas para preparar a mão de obra, visando atender a demanda do mercado de trabalho. Os autores, agora mencionados, falam da necessidade de ressignificação na educação profissional. Acreditamos que a teoria vygotskyana pode contribuir de forma relevante, ofertando imperiosas reflexões para a prática 
FEITOSA, M. da S.; MARTINS, J. P. L.; TAVARES, S. L. P.; LEĀES, P. G.; OLIVEIRA, C. A. de.(2019).

A educação profissional e tecnológica na ótica de Lev Vygotsky: pressupostos teóricos e contribuições

docente na educação profissional, conforme veremos a seguir.

Refletirmos acerca das contribuições de Vygotsky para a educação profissional é pensar num tipo de educação que considere o homem como um ser histórico-cultural e como agente de transformação do meio em que vive. Nessa perspectiva, podemos vislumbrar que os estudos de Vygotsky foram fortemente influenciados pelo materialismo histórico dialético, pois como afirma Rego (1995, p. 98): "nesta abordagem, o sujeito produtor de conhecimento não é um mero receptáculo que absorve e contempla o real nem o portador de verdades oriundas de um plano ideal pelo contrário é um sujeito ativo...". Sendo assim, nota-se que práticas pedagógicas em que os educandos são vistos apenas como meros receptores dos processos de aprendizagem, não são condizentes com a teoria vygotskiana, pois esta visa privilegiar a interação, a troca de conhecimentos e o dinamismo que envolve os processos de ensino-aprendizagem.

De acordo com os estudos de Vygotsky, explicitados por Rego (1995), o desenvolvimento ocorre mediante quatro dimensões, a saber: filogenéticas, ontogenética, sociogênese e a microgênese. A primeira dimensão busca compreender a história evolutiva de uma determinada espécie, os limites e possibilidades da mesma, a segunda revela como se processa o desenvolvimento do indivíduo pertencente a uma determinada espécie, a terceira analisa a influência do meio social na vida do indivíduo e as transformações decorrentes desta e, a última, leva em consideração que cada fenômeno psicológico varia de sujeito para sujeito, fazendo uma análise mais profícua de cada indivíduo. Pelas explicitações acima, podemos entender que Vygotsky considera o ser humano a partir de suas formações genéticas e principalmente sociais. Infere-se, ainda, que cada ser humano tem suas singularidades. Ao enfatizar as particularidades individuais do ser humano, a valorização do ritmo de aprendizagem de cada um, por exemplo, fugimos das teorias deterministas e da não homogeneização das turmas. Um ponto muito importante das observações de Vygotsky para a educação, pois contribui para uma aprendizagem mais significativa.

Ainda de acordo com esta (Ibidem, 1995), Vygotsky preocupou-se em analisar como ocorria a internalização das práticas culturais no sujeito. Ela afirma que compreender como ocorre a passagem do movimento de ações realizadas nas esferas sociais (fator interpsiclógico) para o plano interno, intramental (intrapsicológico) ganhou papel de destaque nos estudos realizados pelo autor. Mais uma vez, notamos como as relações desenvolvidas nos ambientes sociais (escola, família, comunidade que o sujeito está inserido) são importantes para os processos constitutivos de aprendizagem, segundo aponta Vygotsky.

Outros dois conceitos dos estudos de Vygotsky que visam contribuir para uma pedagogia mais interacionista na educação profissional, por exemplo, são a mediação e zona de desenvolvimento proximal. À luz da teoria de Vygotsky, a mediação é compreendida como a relação estabelecida do homem com o meio ambiente e também com os outros homens, destacando que essa mediação ocorre através de instrumentos e signos (Ibidem, 1995). Os instrumentos são vistos como meios auxiliares que usamos para atingir um determinado fim. Exemplificando: usamos a lousa para explicar algum assunto da aula. Neste caso, a lousa seria o instrumento de mediação usado pelo professor. E os signos, o que são? Segundo Fontana e Cruz $(1999$, p.59) "Tudo o que é utilizado pelo homem para representar, evocar ou tornar presente o que está ausente constitui um signo: a 
FEITOSA, M. da S.; MARTINS, J. P. L.; TAVARES, S. L. P.; LEĀES, P. G.; OLIVEIRA, C. A. de.(2019).

A educação profissional e tecnológica na ótica de Lev Vygotsky: pressupostos teóricos e contribuições

palavra, o desenho, os símbolos [...], etc". Vigotsky considerava a linguagem como um o sistema de signo fundamental, o mais importante para o ser humano. Dessa forma, quando os educadores e educadoras percebem a importância do trabalho mediado, da interação com o grupo, certamente, tem-se práticas educativas transformadoras, em que o sujeito é dela participante e agente de transformação. Sendo assim, concordamos com Bedim; Oliveira, 2012 (apud MOURA et al, 2016, p.110) quando afirma que:

Vygotsky apresenta um conceito de sujeito que não se organiza internamente e nem é apenas um simples fenômeno dos estímulos do ambiente. Esta concepção é fundamental para pensarmos que o sujeito não é apenas condicionado pelo meio ou interage com ele de forma neutra, mas, também, o produz e o afeta. Nesse aspecto, o conceito de mediação é fundamental na aprendizagem, pois é através dela e da internalização dos símbolos que os processos psicológicos complexos, característicos do homem, são formados.

Ainda no que tange a relevância do trabalho mediado, destacamos aqui o uso das metodologias ativas, em que se percebe o educando como partícipe ativo na construção de sua aprendizagem. De acordo com Abreu 2009 (apud DIESEL, MARTINS e BALDEZ, 2017, p.273), "ao contrário do método tradicional, que primeiro apresenta a teoria e dela parte, o método ativo busca a prática e dela parte para a teoria". As autoras agora mencionadas, também destacam os princípios que regem as metodologias ativas, a saber: o aluno é visto como centro do processo de aprendizagem dispõe de autonomia, o professor é tido como mediador/facilitador, há uma problematização e reflexão da realidade e valorização do trabalho em equipe. Portanto, em consonância com os princípios agora elencados, no método ativo, o educando é construtor do seu próprio conhecimento, problematiza e faz reflexões acerca da realidade que o circunda, tornandose, também, um agente de transformação.

Após esclarecermos acerca da importância da mediação, convém-nos debater, agora, sobre ZDP - Zona de Desenvolvimento Proximal, outro conceito desenvolvido por Vygotsky que é de suma relevância para práticas educativas na educação profissional, vejamos por que. De acordo com Vygotsky (1991, p.58) "A Zona de Desenvolvimento Proximal define aquelas funções que ainda não amadureceram, mas que estão em processo de maturação, funções que amadurecerão, mas que estão, presentemente, em estado embrionário". Com base no que foi dito agora, para entender o que Zona de Desenvolvimento Proximal, cabe primeiro entender como se dá o desenvolvimento do aluno, ou seja, é importante saber o que já foi aprendido pelo aluno de fato e também o que ele ainda é capaz de aprender. Baseado nisso, divide-se o desenvolvimento do aluno em dois níveis: Nível de Desenvolvimento Real e o Nível de Desenvolvimento Potencial.

Andrade (2007) diferencia esses dois níveis, afirmando que o Nível de Desenvolvimento Real é tudo aquilo que o aluno pode fazer de forma independente, sem ajuda de ninguém; já a Zona de Desenvolvimento Potencial, é o que está por vir, é aquilo que ainda não foi apreendido pelo aluno, e que, consequentemente, dependerá da mediação do professor. Assim, cabe ao professor desenvolver estratégias pedagógicas para que o desenvolvimento real seja impulsionado e aflorado. É então, a partir desses dois níveis que Vygotsky formula o que conhecemos por Zona de Desenvolvimento 
FEITOSA, M. da S.; MARTINS, J. P. L.; TAVARES, S. L. P.; LEĀES, P. G.; OLIVEIRA, C. A. de.(2019).

A educação profissional e tecnológica na ótica de Lev Vygotsky: pressupostos teóricos e contribuições

Proximal.

Segundo Silva (2007, p. 54) a ZDP “[...] é um domínio psicológico em constantes transformações, aquilo que a criança é capaz de fazer com a ajuda de alguém hoje, ela conseguirá fazer sozinha amanhã". Vale salientar que este é um processo em constante dinamicidade. Podemos ver nas palavras do autor, que a Zona de Desenvolvimento Proximal é o local onde a criança tem todo o potencial para se desenvolver, destacando o lugar específico onde o professor deva fazer a mediação.

Certamente, quando o professor considera as particularidades de cada indivíduo e o nível de aprendizado que este se encontra, procurando incentivá-lo a novos desafios, teremos uma aprendizagem expressiva. Podemos citar algumas formas de o professor trabalhar nesta base teórica desenvolvida por Vygotsky (Zona de Desenvolvimento Proximal). Por exemplo, o educador incentivar a realização de trabalhos em grupos, em que alunos com diferentes níveis de ensino possam interagir e trocar experiências com os outros; podemos também citar a monitoria, pois esta permite que, aquele aluno que domina assuntos de uma determinada disciplina, possa aperfeiçoar ainda mais este conhecimento quando compartilha com seus colegas de classe o que já internalizou. Com estas atitudes, os educandos vão se tornando mais protagonistas do processo de aprendizagem, pois como enfatiza Vygotsky 2001, p.452 (apud MAGALHÃES, 2017, p.2):

Até hoje o aluno tem permanecido nos ombros do professor. Tem visto tudo com os olhos dele e julgado tudo com a mente dele. Já é hora de colocar o aluno sobre as suas próprias pernas, de fazê-lo andar e cair, sofrer dor e contusões e escolher a direção.

Ainda no que tange à ZDP, é relevante que o professor sempre anteponha ao desenvolvimento do aluno, ensinando aquilo que o aluno está em fase de aprendizado, pois não adianta ensinar o que o aluno já sabe. Além disso, o professor deve estar atento à individualidade de cada aluno, conforme já foi assinalado, e é nesse contexto que surge mais um conceito trabalhado por Vygotsky: a Internalização. Os autores abaixo, assim explanam:

A teoria sociocultural tem como pressuposto que as atividades humanas e o seu desenvolvimento cognitivo seja produzido pelo processo de internalização da interação social em contextos culturais, sendo mediadas pela linguagem ou outros sistemas simbólicos podendo ser mais bem compreendidas quando investigadas no seu desenvolvimento histórico. (OLIVEIRA e SILVA, 2018, p. 352).

Oliveira (2010) também menciona que o aluno não é apenas parte ativa do processo, mas desenvolve uma relação também interativa, porque é a partir das relações inter e intrapessoais que se formam os conhecimentos. Fica claro, nos autores, que o desenvolvimento e o processo de conhecimento procedem de fora para dentro, levando em consideração o ambiente, o contexto social em que o aluno estará inserido.

Ainda no que diz respeito às contribuições da teoria vygotskyana para a Educação Profissional, podemos citar duas vertentes teóricas que derivam dos pensamentos desse estudioso: a Teoria da Atividade e as Comunidades de Práticas. Segundo Kaptelinin e Nardi, 2006, p. 10 (apud 
FEITOSA, M. da S.; MARTINS, J. P. L.; TAVARES, S. L. P.; LEĀES, P. G.; OLIVEIRA, C. A. de.(2019). A educação profissional e tecnológica na ótica de Lev Vygotsky: pressupostos teóricos e contribuições

BARATO,2008, p.12):

$\mathrm{Na}$ Teoria da Atividade as pessoas atuam com tecnologia; as tecnologias são duplamente planejadas e usadas num contexto onde há pessoas com intenções e desejos. As pessoas atuam como sujeitos no mundo, construindo e concretizando suas intenções e desejos como objetos.

Pela citação acima, percebemos que na Teoria da Atividade há uma valorização dos saberes dos sujeitos, de suas intenções e particularidades e que o indivíduo é um agente de transformação social. 0 autor ainda acrescenta (Ibidem, 2008) que podemos definir a atividade como uma técnica qualquer em que se nota o sujeito agindo e interagindo com o mundo.

As Comunidades de Práticas também priorizam a interação social e a busca por melhorias ou aprimoramento de um aprendizado. Vemos, nas Comunidades de Práticas, mais uma forma de potencializar o aprendizado na Educação Profissional, pois o educador como mediador do processo de aprendizagem, pode debater e refletir com os educandos acerca de formações de Comunidades de Práticas no ambiente escolar e na própria localidade que reside. De acordo com Wenger (2010) apud Fernandes et al (2016, p. 45) ,as Comunidades de Práticas são assim definidas:

As CoPs são formadas por pessoas que voluntariamente compartilham de um mesmo interesse ou paixão, interagem regularmente, trocam informações e conhecimento, buscam sustentar a comunidade e compartilham do aprendizado, de maneira que podem ser caracterizadas por apresentarem as seguintes dimensões: empreendimento conjunto, envolvimento mútuo e repertório compartilhado.

Portanto, conforme os diálogos apresentados neste estudo, os pressupostos teóricos desenvolvidos por Vygotsky podem muito contribuir com a educação profissional, como citamos pelas reflexões a partir dos conceitos de Mediação, Zona de Desenvolvimento Proximal e Internalização. Também fizemos um breve comentário acerca de duas vertentes teóricas em que se notam o pensamento ygotskyano: a Teoria da Atividade e as Comunidades de Práticas. Estas também desempenham papel relevante para a construção de uma educação profissional em que o educando seja ativo, interaja e transforme à comunidade do qual faz parte.

\section{Conclusões}

A proposta deste artigo foi compreender como a teoria de Vygotsky pode contribuir com as práticas pedagógicas na educação profissional e tecnológica. Fizemos, assim, uma análise dos principais conceitos trabalhados por este autor, que podem potencializar os processos de ensinoaprendizagem na educação profissional, a saber: mediação, zona de desenvolvimento proximal e interação. Tais pressupostos revelam o quão é importante que o educador desenvolva um trabalho mediado, em que prevaleça a interação, a troca de saberes e valorização das experiências de educador e educando. Na perspectiva de Vygotsky, o educando é um sujeito ativo e partícipe do processo de conhecer e aprender. Sendo assim, a abordagem sociointeracionista preconizada por Vygotsky vai de encontro às práticas pedagógicas vislumbradas no ensino tradicional. Isso porque, 
FEITOSA, M. da S.; MARTINS, J. P. L.; TAVARES, S. L. P.; LEĀES, P. G.; OLIVEIRA, C. A. de.(2019).

A educação profissional e tecnológica na ótica de Lev Vygotsky: pressupostos teóricos e contribuições

nesse tipo de enfoque, o aluno é visto como um ser passivo, em que se nota como único protagonista o professor, este, nesta abordagem, é o detentor do saber. Já a teoria vygotskyana vem demonstrar justamente o oposto: que as práticas pedagógicas devem levar em consideração o contexto social e cultural do indivíduo, destacando, também, as singularidades e potencialidades de cada sujeito.

Conforme foi explicitado neste estudo, a educação profissional, desde sua gênese, é vislumbrada numa perspectiva dualista: ensino propedêutico para a elite e profissional para as classes trabalhadoras. Destacamos, também, expectativas de mudanças, principalmente com as proposições de Araújo e Frigotto $(2015$, p.68) os quais revelaram que se devem formar os indivíduos em suas múltiplas capacidades: "de trabalhar, de viver coletivamente e agir autonomamente sobre a realidade, contribuindo para a construção de uma sociabilidade de fraternidade e de justiça social". Corroborando com essas reflexões, citamos as inferências de Barato (2008) por meio das abordagens da Teoria da Atividade e das Comunidades de Práticas, que se revelam como vertentes propícias ao desenvolvimento de uma pedagogia mais reflexiva e emancipadora.

Importante destacar, aqui, o pensamento de Freire (1996, p.21) quando coloca: [...] "ensinar não é transferir conhecimento, mas criar as possibilidades para a sua própria produção ou a sua construção. Quando entro em uma sala de aula devo estar sendo um ser aberto a indagações, à curiosidade, às perguntas dos alunos, às suas inibições...". Sendo assim, como educadores e educadoras faz-necessário refletir continuamente sobre as práticas pedagógicas adotadas na trajetória profissional. Uma imersão na teoria de Vygotsky se delineia como uma opção para este caminho.

Portanto, acredita-se que as teorias de Vygotsky podem contribuir com práticas mais significativas na educação profissional, enfatizando uma perspectiva mais emancipadora dos sujeitos, que valoriza os conhecimentos prévios dos alunos, uma maior integração entre teoria e prática, valorização da diversidade cultural, dentre outras nuances. Como sugestão para outros pesquisadores, apontamos uma reflexão mais ampla acerca da Teoria da Atividade e das Comunidades de Práticas, objetivando, assim, que novos aprofundamentos sejam realizados e que contribuam para as práticas pedagógicas na educação profissional e tecnológica.

\section{Referências}

ARAÚJO, W. S. (2016). Das Escolas Técnicas Federais aos Institutos Federais: A licenciatura em Física no Campus Goiânia do IFG. Dissertação (Mestrado em Ciência e Matemática)- Universidade Federal de Goiás, Goiânia,2016.

BARATO, Jarbas Novelino. Conhecimento, Trabalho e Obra: uma proposta metodológica para a educação profissional. Boletim Técnico do Senac, v. 34, n. 3, 2008.

BISPO, F. C. S. Formação Profissional e cidadania: a contribuição do PRONATEC. XII Simpósio de Gestão e Tecnologia, Resende, 2015. Disponível em: <https://www.aedb.br/seget/arquivos/artigos15/24622371.pdf>. Acesso em: 20 abr. 2019. 
FEITOSA, M. da S.; MARTINS, J. P. L.; TAVARES, S. L. P.; LEÃES, P. G.; OLIVEIRA, C. A. de.(2019)

A educação profissional e tecnológica na ótica de Lev Vygotsky: pressupostos teóricos e contribuições

BRASIL. Ministério da Educação. Centenário da Rede Federal de Educação Profissional e Tecnológica. 2009 a.Disponível em: http://portal.mec.gov.br/setec/arquivos/centenario/historico_educacao_profissional.pdf. Acesso em: 18 abr. 2019

BRASIL. Histórico da Educação Profissional e Tecnológica no Brasil. 2018. Disponível em: <http://portal.mec.gov.br/sinaes/30000-uncategorised/68731-historico-da-educacao-profissional-etecnologica-no-brasil>. Acesso em: 19 abr. 2019.

CAETANO, Saul Silva; VON LINSINGEN, Irlan. Concepções Sobre o Conhecimento Tecnológico e a Estrutura Curricular dos Cursos Técnicos. Revista Brasileira de Ensino de Ciência e Tecnologia, [s.l.], v. 4, n. 3, p.35-49, 15 dez. 2011. Universidade Tecnologica Federal do Parana (UTFPR). http://dx.doi.org/10.3895/s1982$\underline{873 \times 2011000300002 .}$.

DE LIMA ARAUJO, Ronaldo Marcos; FRIGOTTO, Gaudêncio. Práticas pedagógicas e ensino integrado. Revista Educação em Questão, v. 52, n. 38, p. 61-80, 2015.

DIESEL, Aline; BALDEZ, Alda Leila Santos; MARTINS, Silvana Neumann. Os princípios das metodologias ativas de ensino: uma abordagem teórica. Revista Thema, v. 14, n. 1, p. 268-288, 2017

FERNANDES, Flávia Roberta et al. Comunidades de prática: uma revisão bibliográfica sistemática sobre casos de aplicação organizacional. AtoZ: novas práticas em informação e conhecimento, [S.l.], v. 5, n. 1, p. 44-52, jul. 2016. ISSN 2237-826X. Disponível em: https://revistas.ufpr.br/atoz/article/view/46691/28744. Acesso em: 18 abr. 2019. Doi :http://dx.doi.org/10.5380/atoz.v5i1.46691.

FITTIPALDI, Cláudia Bertoni. Conceitos centrais de Vygostky: implicações pedagógicas. Revista Educação-UNG Ser, v. 1, n. 2, 2007.

FONTANA, Roseli. CRUZ, Maria Nazaré da. Psicologia e trabalho pedagógico. São Paulo: Atual, 1997.

FREIRE, P. (1996). Pedagogia da autonomia: saberes necessários à prática educativa. São Paulo: Paz e Terra, 1996.

GARCIA, A. de C.; DORSA, A. C.; OLIVEIRA, E. M. de. EDUCAÇÃO PROFISSIONAL NO BRASIL: origens e trajetórias. Vozes dos Vales, Diamantina, v. , n. 13, p.1-18, maio 2018.

GIL, A. C. Métodos e Técnicas de Pesquisa Social. 5 ed. São Paulo: Atlas, 2007

LIMA, S. de C. DA SUBSTITUIÇÃO DE IMPORTAÇÕES AO BRASIL POTÊNCIA:: Concepções do desenvolvimento 1964-1979. Aurora, São Paulo, v. 7, p.34-44, jan. 2011

MAGALHÃES, Cláudio Márcio. Da sala à praça: motivação, mediação e Vigotsky para entender o comportamento. Comunicação e Sociedade, v. 33, p. 347-367, 2018.

MOREIRA, Marco Antonio. Teorias de aprendizagem. São Paulo: Editora pedagógica e universitária, 1999. 
FEITOSA, M. da S.; MARTINS, J. P. L.; TAVARES, S. L. P.; LEĀES, P. G.; OLIVEIRA, C. A. de.(2019).

A educação profissional e tecnológica na ótica de Lev Vygotsky: pressupostos teóricos e contribuições

MOURA, Dante Henrique. EDUCAÇÃO BÁSICA E EDUCAÇÃO PROFISSIONAL E TECNOLÓGICA:: DUALIDADE HISTÓRICA E PERSPECTIVAS DE INTEGRAÇÃO. Holos, Natal, v. 2, p.4-30, 2007.

MOURA, Dante Henrique; LEITE LIMA FILHO, DOMINGOS; RIBEIRO SILVA, MÔNICA. Politecnia e formação integrada: confrontos conceituais, projetos políticos e contradições históricas da educação brasileira. Revista Brasileira de Educação, v. 20, n. 63, 2015.

MOURA, Elaine Andrade et al. Os planos genéticos do desenvolvimento humano: a contribuição de vigotski. Revista Ciências Humanas, v. 9, n. 1, 2016.

OLIVEIRA, Jamille De Amorim; SILVA, Yara Fonseca de Oliveira e. PERFIL E PERCEPÇÕES SOBRE A PRÁTICA PEDAGÓGICA DO PROFESSOR BACHAREL NA EDUCAÇÃO PROFISSIONAL. HOLOS, [S.l.], v. 3, p. 348-366, set. 2018. ISSN 1807-1600. Disponível em: <http://www2.ifrn.edu.br/ojs/index.php/HOLOS/article/view/6998>.

PACHECO, E. M.; MORIGI, V. (Org.). Ensino Técnico, Formação Profissional e Cidadania: A revolução da Educação Profissional e Tecnológica no Brasil. Porto Alegre, Tekne, 2012.

PACHECO, E. M.; PEREIRA, L. A. C.; DOMINGOS M. Educação Profissional e Tecnológica: das escolas de aprendizes artífices aos institutos federais de educação, ciência e tecnologia. T\&tc Amazônia, Manaus, p.2-7, fev 2009.

PAMPLONA, R. M. As relações entre o estado e a escola: um estudo sobre o desenvolvimento da educação profissional de nível médio no brasil. 2008. 143 f. Dissertação (Mestrado) - Curso de Mestrado em Ciências, Universidade Federal Rural do Rio de Janeiro Instituto de Agronomia, Seropédica, 2008.

PRODANOV, Cleber Cristiano; DE FREITAS, Ernani Cesar. Metodologia do trabalho científico: métodos e técnicas da pesquisa e do trabalho acadêmico-2a Edição. Editora Feevale, 2013.

REGO, Teresa Cristina. Vygotsky. Uma perspectiva histórico-cultural da educação. Petrópolis (RJ): Vozes, 1995.

SEVERINO, Antônio Joaquim. Metodologia do trabalho científico. 23. ed. rev. e atual. São Paulo: Cortez, 2007.

VIEIRA, Marilandi Maria Mascarello; VIEIRA, Josimar de Aparecido. PRODUÇÃO DE CONHECIMENTOS NA EDUCAÇÃO PROFISSIONAL. HOLOS, [S.l.], v. 2, p. 24-36, mar. 2014. ISSN 1807-1600. Disponível em: http://www2.ifrn.edu.br/ojs/index.php/HOLOS/article/view/1994. Acesso em: 05 abr. 2019. doi:https://doi.org/10.15628/holos.2014.1994.

VYGOTSKY, Lev Semenovich. A formação social da mente. $4^{a}$ edição brasileira. São Paulo, Martins, 1991. 